\title{
CON'TRIBU'TION
}

TO THE

\section{STATISTICS OF CANCER.}

BY

W. M. BAKER, M.R.C.S.

COMMUNICATED BY

JA M ES PAGET, V.P.R.S.

Received June 23rd.-Read June 24th, 1862.

The contribution to the statistics of cancer here presented to the Royal Medical and Chirurgical Society has been collected from notes of 500 of the cases taken by Mr. Paget between the years 1843 and 1861. The conclusions to be drawn from them may be added to, or incorporated with, those made by Mr. Sibley, and published in the 'Transactions,' vol. xlii. The number of cases is nearly the same as that from which his tables were constructed; and they are tabulated on the same general plan. Such additions as they may make to the facts which he has deduced, or such differences of conclusion as they may suggest, may be ascribed to their having been observed in an entirely different field, and, for the most part, in private practice.

The cases were recorded by Mr. Paget as they occurred, and without any reference to the particular kind of cancer, its seat, or its influence on the duration of life; none were either selected or omitted for any special reason. But in the 500 cases for which these tables are constructed only such cancers have been included as were external or might be called surgical, the so-called medical cases being omitted. Cases of cancer of the larynx, œsophagus, rectum, and bladder are included, but not those of the uterus, the cases 
of which, in Mr. Paget's notes, were not sufficiently numerous to allow of any safe deductions worth adding to those arrived at from the very large number studied by Mr. Sibley.

The whole of the cases have come under Mr. Paget's own observation, and been diagnosed as cancer by him : in a large part of them the naked-eye appearances have been compared with the microscopical. They include hospital and private patients, in the proportion of about two fifths hospital to three fifths private.

Of the several kinds of cancer, five only, viz., scirrhous, medullary, melanotic, osteoid, and epithelial, have been taken. The villous and colloid varieties have been omitted, chiefly on account of their comparative rarity, and, consequently, the small number of cases noted by one observer.

\section{Primary seat.}

The various organs were affected primarily, in the following proportion :

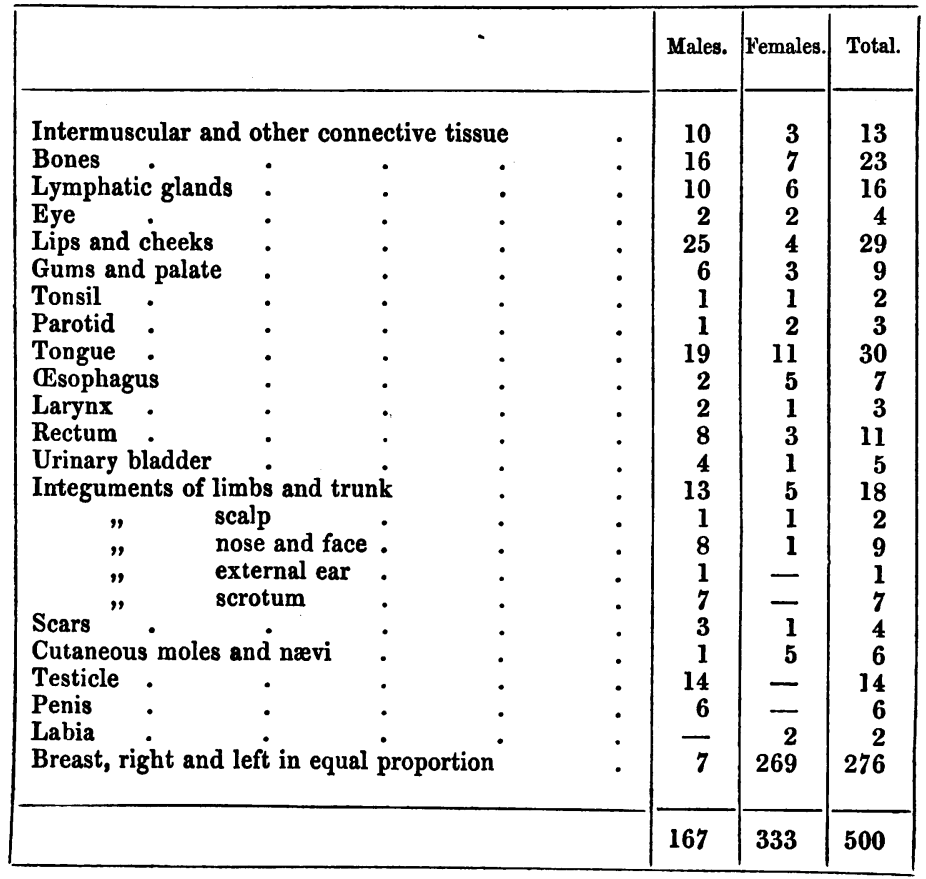


The far greater liability of females to be attacked by cancer is here well shown, the number of cases in them being almost double that in males; but it will be seen at once that this is due to the cases of cancer of the breast, for, on subtracting these from each table respectively, we have 160 cases of cancer in males, and 64 in females.

The results in Mr. Sibley's table accord mainly with the preceding, but, from his including cancer of the uterus, the proportion of females affected is much larger. On subtracting, however, the cases in the reproductive organs and breast in both sexes, as well as those in internal organs, which are added to his collection, the proportion remaining is considerably higher in males than females.

From the present cases being taken indifferently as they occurred in practice, and from their being, almost all of them, such as would apply for surgical help exclusively, the numbers may be taken to represent very fairly the comparative liability to cancer of each of the organs included in the table.

\section{Variety of cancer, distribution, \&c.}

In the whole 500 cases the per-centage of each kind of cancer was as follows :

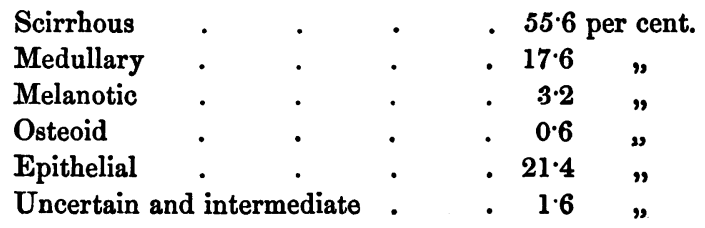

On further analysing the manner in which each variety of cancer is distributed, we find that, with rare exceptions, each organ is attacked by one form of the disease, almost exclusively.

This will be seen from the following table. 


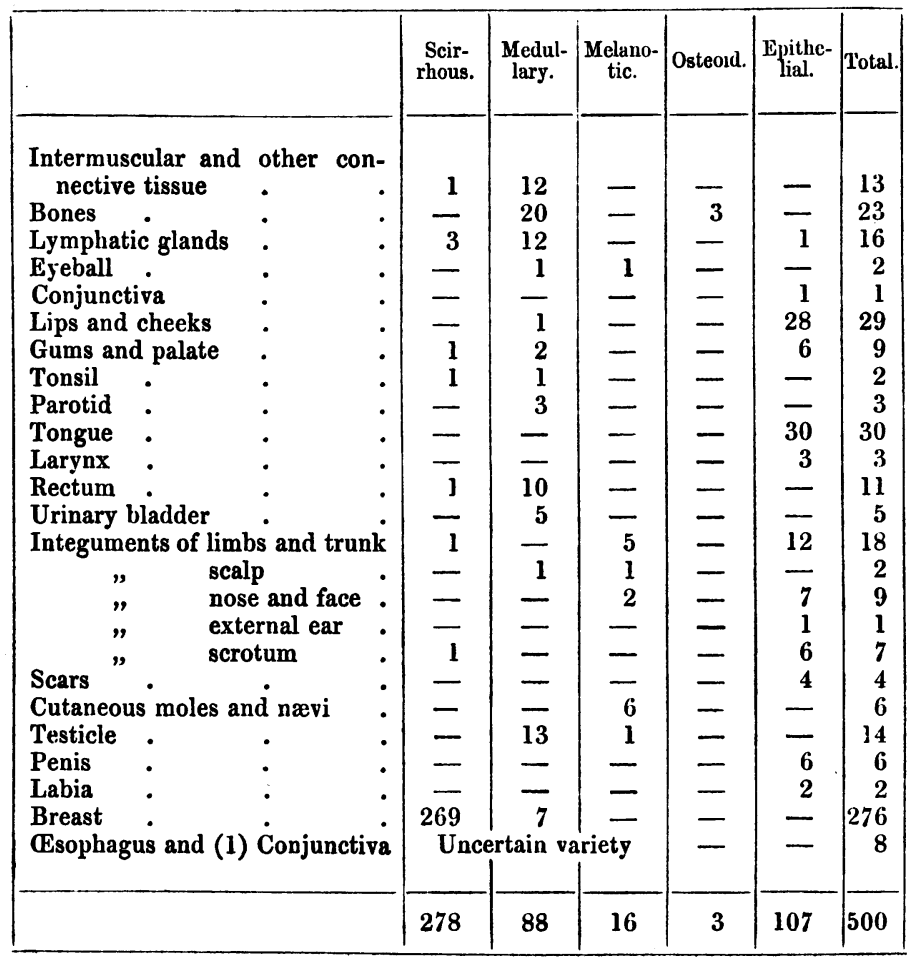

Age.

No age is entirely free from a certain liability to cancer, but there are comparatively few cases among the very young. Amongst the present cases the earliest age at which the disease occurred was in a male infant, in whom medullary cancer of the ilium began when it was fifteen months old. A case of melanosis of the eyeball occurred in a male, aged two years; and two more of melanosis of the integuments in infants, three years old each, one male and the other female. The oldest patient was a woman, who began to suffer from epithelial cancer of the tongue when she was ninety years old. 
It might be almost said to be a rule, for the external organs, that medullary and melanotic are the cancers of youth and early adult age, scirrhous, that of middle life, and epithelial, of middle and old age, so much do they affect these periods respectively; but a wide margin for exceptions must be allowed to each of them.

No case of cancer, other than medullary and melanotic, began before the age of twenty, with two exceptions, at the age of fifteen and seventeen, which were osteoid.

The majority of all the cases of medullary cancer in external organs, with one exception, began before the age of forty, and those in the bones and connective tissue before thirty. The exception was the breast, in which the seven cases of medullary cancer began between forty and seventy. This form of cancer, when attacking internal organs, begins, apparently, at a much later period of life. In the following table the rectum and bladder are examples of this fact, and, I believe, medullary disease of the pylorus is most frequent at about the same age.

Only five cases of scirrhous cancer of the breast began before thirty years of age, and the largest number, within ten years, occurred between forty and fifty. The cases of this form of cancer in other organs are not numerous enough for any conclusions to be drawn from them.

Only eight cases of epithelial cancer began before thirty, comparatively few before forty, and the largest number within ten years, between fifty and sixty years of age.

These particulars may be seen in detail by referring to the following table. By comparing it with that which precedes, the frequency of cancer of each kind, at each age, may be found without difficulty, as the several organs are so exclusively affected by their own particular form of the disease.

The numbers at the top represent the age, in periods of ten years, at which the disease began. 


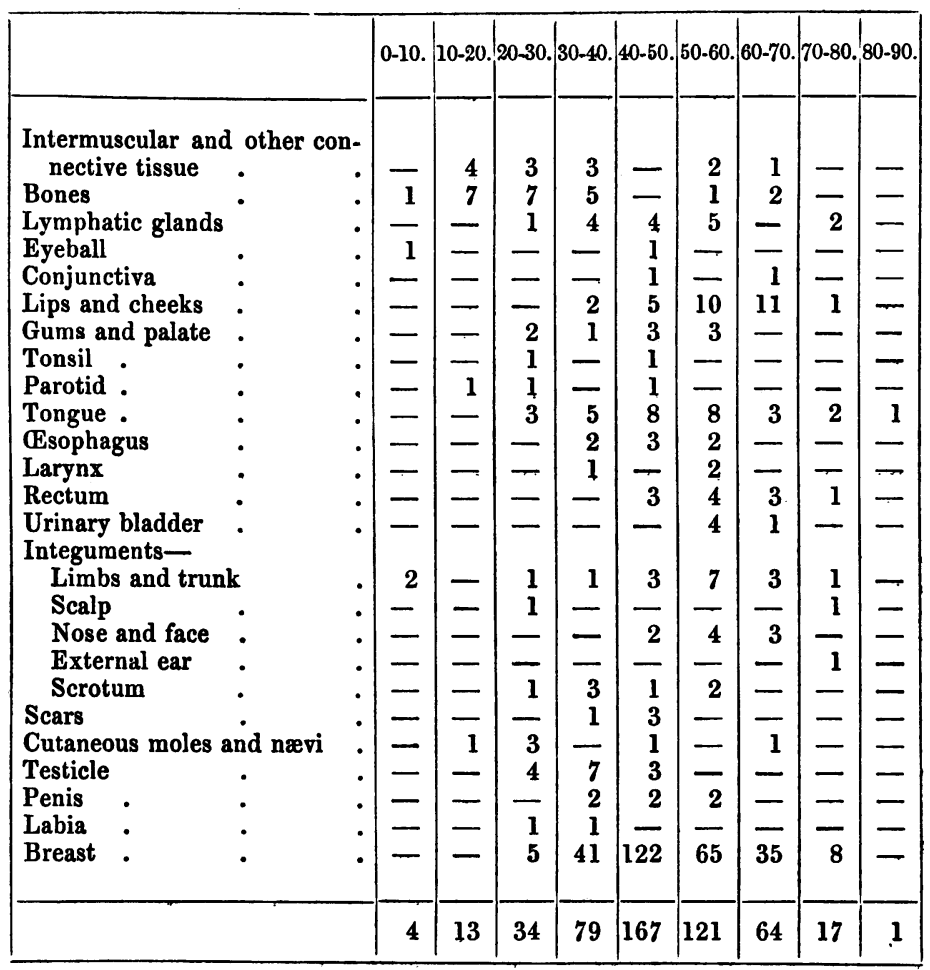

Sex.

The influence of sex upon the production of cancer at each age is shown in the following table.

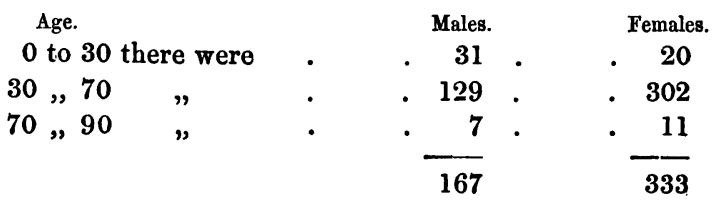

The difference in the two sexes is, therefore, greatest during the period most prone to cancer of the breast. When the breast and organs of generation in both sexes are excluded, the proportion is as follows : 


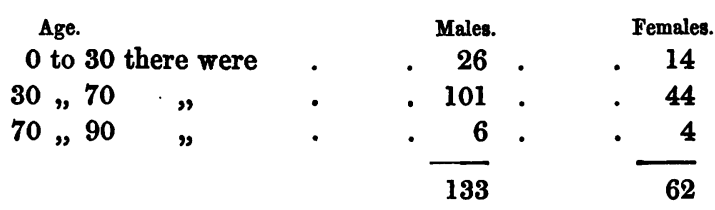

The following table has been made in order to show the relative frequency of cancer, at each age, in proportion to the whole population living at the same period. As it includes, like the others, only a few of the internal organs, which are affected most frequently in advanced age, it cannot be taken as a test of the frequency of cancer, except in external organs. For the same reason, and because a comparatively larger number of medullary cancers are thereby omitted, and of scirrhous included, the result does not clash with the statement in Mr. Paget's lectures, ${ }^{1}$ that cancer increases in frequency from earliest to latest life.

The numbers represent the relative proportion, 1 being taken for convenience as the lowest.

\begin{tabular}{|c|c|c|c|c|c|c|}
\hline \multicolumn{3}{|c|}{ Maues. } & & \multicolumn{3}{|c|}{ Females. } \\
\hline Age. & & & & Age. & & \\
\hline 0 to 10 & - & $1 \cdot 0$ & & 0 to 10 & . & $1 \cdot 0$ \\
\hline 20 & . & $4 \cdot 3$ & & . 10,20 & . & $3 \cdot 8$ \\
\hline 20,30 & . & $9 \cdot 8$ & & . 20,30 & & $26 \cdot 2$ \\
\hline 30,40 & . & . 19.6 & & . 30,40 & & - $108 \cdot 7$ \\
\hline 40,50 & . & . 32.4 & & . 40,50 & & - $371 \cdot 0$ \\
\hline 50,60 & . & - $57 \cdot 3$ & & . 50,60 & & - $288 \cdot 0$ \\
\hline 60,70 & . & . 40.8 & & . 60,70 & & . 240.5 \\
\hline 70,90 & . & . $21 \cdot 5$ & & . 70,80 & - & $89 \cdot 3$ \\
\hline
\end{tabular}

The highest number among males, between fifty and sixty, and among females, between forty and fifty, might have been anticipated from the larger proportion, in the one, of epithelial cancer, and in the other, of scirrhous.

1 'Lectures on Surgical Pathology,' vol. ii, p. 546. 
Social condition, \&c.

Influence of marriage, \&c.-The condition of the female patients, whether single, married, or widow, was noted in 260 cases of cancer of the breast, the proportion being -

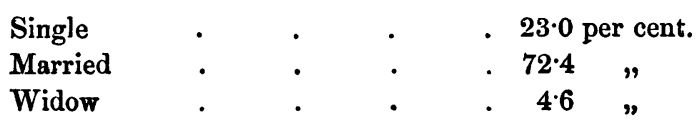

The per-centage of each in fifty-four cases of cancer in other organs was-

$\begin{array}{lllll}\text { Single } & . & . & . & . \\ \text { Married } & . & . & . & .68 .5 \text { per cent. } \\ \text { Widow } & . & . & . & : 11.1 "\end{array}$

The per-centage of single women in cases of cancer of the breast is smaller than that in the female population generally, ${ }^{1}$ and the table would therefore indicate a greater liability in the married than the single to be attacked by cancer in this organ.

The proportion agrees very closely with that given by Mr. Sibley, if the married and widows be taken together; the latter forming, in his table, a larger number than the single.

\section{Pregnancy.}

Of 163 married women suffering from cancer of the breast, 126 were fruitful, 37 barren. Of 25 cases of cancer in other organs, 22 were fruitful, 3 barren. But the number is too small to allow of a very fair comparison being made between them and the cancers of the breast in this respect.

\section{Catamenia, \&s.}

In 75 cases of cancer of the breast, between the ages of forty and fifty-five years, the state of the catamenia at the time of beginning of the cancer was ascertained.

1 See 'Insurance Guide and Handbook,' London, 1857. 
The disease began in-

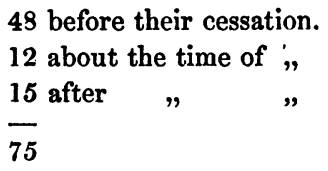

State of health, \&c.

The state of the patient's health at the beginning of the disease was recorded in 437 cases of cancer of all kinds, and of these-

72.5 per cent. were in good health.

$19 \cdot 7 \quad, \quad$ in indifferent health.

$7 \cdot 8 "$ " in bad health.

It would seem, therefore, as if no conclusion, with respect to the constitutional origin of cancer, can be drawn from the good or bad condition of the patient's general health at the time of its first appearance.

Some difference, but not very much, existed between the varieties of cancer in this particular.

In scirrhous cancer 5.2 per cent. were in bad health,

In medullary , $10.9 \quad, \quad$,

In epithelial ", $9 \cdot 7 \quad, \quad$,

when the cancer was first noticed.

\section{Inheritance.}

The presence or absence of cancer in other members of the patient's family was recorded in 322 instances, cancer of all kinds being included in this number. 78 of these, or $24 \cdot 2$ per cent., had had one or more cancerous relatives : again, 13 of the latter had had two, and 5 had had three, relatives affected with the disease.

The difficulties in obtaining a correct family history from hospital patients are, as Mr. Sibley remarks, considerable, and it is, probably, from the present table including a large number of private cases, in whom the family history would be better known, that the per-centage $(24 \cdot 2)$ is so much greater than that given by him in his paper $\left(8_{4}^{\frac{3}{4}}\right)$. 
This is made more likely still from the per-centage of cancerous inheritance being, among the private cases, $27 \cdot 4$, against $17 \cdot 9$ among hospital patients. The kind of cancer was not always the same in all the members of the family who were attacked. ${ }^{1}$

Recurrence after operation, \&c.

The following tables have been made in order to show the times of recurrence of the disease after operation. No case has been included unless the operation was a complete one, the whole of the apparent disease being removed; and cases in which lymphatic glands that were sensibly enlarged at the time of operation afterwards increased, with signs of cancer in them, have been also omitted.

The first table shows the date of recurrence in the several varieties of cancer, the figures at the top representing the number of months after the operation at which the disease recurred, and those opposite the name of the cancer, the number of cases.

\begin{tabular}{|c|c|c|c|c|c|c|c|c|c|c|c|c|}
\hline & 1-3. & 3-6. & 6-12. & $12-18$. & 18-24. & $24-30$ & $30-36$ & $36-42$ & $42-48$ & $48-54$ & $78-84$ & Total. \\
\hline Scirrhous & 9 & 17 & 15 & 9 & 4 & - & 2 & 1 & 1 & 2 & 2 & 62 \\
\hline Medullary & 4 & 6 & 3 & 1 & 2 & - & - & - & - & - & - & 16 \\
\hline Melanotic & 6 & 1 & 1 & - & - & - & - & - & - & 1 & - & 9 \\
\hline Osteoid . & 1 & - & - & 一 & - & - & - & 一 & - & - & - & 1 \\
\hline \multirow[t]{2}{*}{ Epithelial } & 11 & 4 & 7 & 1 & - & - & - & - & - & - & - & 23 \\
\hline & 31 & 28 & 26 & 11 & 6 & - & 2 & 1 & 1 & 3 & 2 & 111 \\
\hline
\end{tabular}

The average date of recurrence in each kind of cancer, as deduced from this table, is-

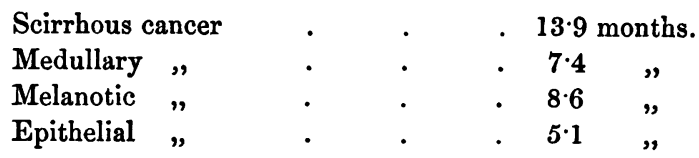

The average here given for scirrhous cancer agrees very. nearly with that stated by Mr. Sibley. The date of recurrence for the other kinds is not given by him.

1 For more details concerning the transmission of cancerous and other tumours, see 'Med. Times and Gazette,' Aug. 22nd, 1857. 
Excepting the breast, the number of cases, when divided, was hardly enough to justify the making a comparison between the dates of recurrence in the several organs.

Some cases, more favorable in their late recurrence, must be added as an appendix to these.

Thus, 6 cases of scirrhous cancer of the female breast are living from thirty-four to ninety-four months after the operation; one case of medullary disease in the forearm forty-two months, and 8 of epithelial from forty-one to a hundred and ten months after it; all of them without any local recurrence.

The most remarkable case is that of a sweep, who began, thirty-five years after the removal of soot-cancer from the scrotum, to suffer from epithelial cancer in the finger and hand. It is probable that this was a case rather of fresh disease, from the same exciting cause, than of recurrence.

There is one source of error in this table, due to the fact that the poorer patients, after leaving the hospital for their own homes, are often lost sight of altogether, unless the rapid return of their complaint obliges them to come again, and seek relief at the same institution. In this way the cases of quick return of the disease would be probably seen again by the operator, while those which were delayed for many months or years would often never be heard of again by him, for many reasons well known to all who have to do with hospital patients.

Perhaps the most striking result from the foregoing table is the great similarity that exists between the several kinds of cancer in their rate of return after removal by operation. The difference so commonly supposed to exist between epithelial cancer and the others, in this respect, disappears altogether, the only point in which the former seems to have an advantage being that more of the cases live without recurrence for a period far beyond the general average.

\section{Influence of age on the recurrence of cancer.}

The influence of age on the recurrence of cancer after removal is, apparently, but slight, or rather its expression is 
but a repetition of the statement as to the influence of the kind of cancer most frequent at each age.

In only one case before the age of thirty did recurrence succeed the operation at a greater distance of time than two years. It was a case of melanosis, returning four and a half years after removal. The cases of scirrhous cancer returning at about the same period were aged forty and fifty years, and the two returning at between six and seven years happened in persons, aged fifty-six and seventy-two years respectively.

\section{Infuence of early and late operation.}

So that the disease is completely removed by the operation, the early or late performance of the latter appears to exercise about the same influence on its progress. This is, most probably, from the early operations being undertaken for the acute and rapidly growing cancers, such as most alarm the patient and make him seek for advice without delay; and these are also such as may be expected to return quickly after removal.

In the following table the date of the operation is expressed by the number of months or years which intervened between the patient's first observation of the cancer and its performance; and the date of recurrence is given also in months which elapsed after the operation, and during which the patient was free from apparent signs of the disease.

The figures, added together, represent, as before, the number of cases.

\begin{tabular}{|c|c|c|c|c|c|c|c|c|c|c|c|}
\hline \multirow{2}{*}{ Date of operation. } & \multicolumn{11}{|c|}{ Date of recurrence. } \\
\hline & $1-3$ & 3.6. & 6-12. & |12-18. & 18-24. & 24-30. & $30-36$. & $36-42$. & $|42-48|$ & 48-54. & $78-84$ \\
\hline $\begin{array}{l}1-3 \text { months } \\
3-6 " \text { " } \\
6-12 \text { " } \\
1-3 \text { years } \\
3-5 " \text { " } \\
5-7 " .\end{array}$ & $\begin{array}{r}4 \\
10 \\
8 \\
6 \\
3 \\
-\end{array}$ & $\begin{array}{l}8 \\
2 \\
7 \\
6 \\
5 \\
\end{array}$ & $\begin{array}{l}2 \\
5 \\
7 \\
4 \\
8 \\
-\end{array}$ & $\begin{array}{l}-3 \\
5 \\
2 \\
1 \\
-\end{array}$ & $\begin{array}{l}\overline{2} \\
\overline{2} \\
1 \\
1\end{array}$ & $\begin{array}{l}\overline{-} \\
\bar{z} \\
\end{array}$ & $\begin{array}{l}\overline{2} \\
\overline{-} \\
-\end{array}$ & $\begin{array}{l}1 \\
- \\
- \\
-\end{array}$ & $\begin{array}{l}- \\
\frac{-}{1} \\
\frac{1}{2}\end{array}$ & $\begin{array}{l}- \\
2 \\
- \\
-\end{array}$ & $\frac{1}{1}$ \\
\hline & 31 & 28 & 26 & 11 & 6 & - & 2 & 1 & 1 & 3 & 2 \\
\hline
\end{tabular}


The average date of recurrence taken from this table was-

Date of operation.
1 to 3 months
3 , 6 "
6 " 12 "
1 " 3 years
3 " 7 "

Date of recurrence.

. $11 \cdot 4$ months.

. $9 \cdot 4$ "

- $12 \cdot 2 \quad$

. $9 \cdot 4$ "

The reason that the recurrences are not more distant from the late operations performed for the chronic cancers is, very possibly, to be found in the fact that so large a proportion of patients apply for relief when such cancers are beginning to increase rapidly, and, therefore, when they are more analogous with those which are acute from the commencement.

In the instances just mentioned of recurrences delayed for a very long time, or of none taking place at all, no relation between either event and an early or late operation was observed. The times of operation varied from one month to three years after the patient's first noticing the cancer; one was operated on seven years, and another nine years, after its first appearance.

The last is a remarkable case, and the more recent history of it has been obtained since the tables of the duration of life were drawn up. The tumour was a medullary cancer, circumscribed, and situated between the muscles of the forearm. It was removed nine years after its first appearance, and the patient is now alive, three and a half years after the operation, without any local return of the disease.

Influence of operation upon the duration of life.

In the tables which follow, and in which the duration of life in those not operated on has been compared with that of cases in which the primary disease was removed, some allowance must be made for the patients included who are still living. As many of these are in good health, and may voL. XLv. 
yet live for a considerable time, the average length of life may be taken to be rather longer than these tables, by themselves, would show.

Thus, among those not operated on, 8 cases of scirrhous cancer of the breast are still living, at periods varying from 54 to 126 months after the first notice of the disease.

Among the cases of operation have been reckoned 8 patients with scirrhous cancer, who are living from 61 to 141 months, and one case 200 months, after its first appearance; 4 of medullary, at $12,73,76$, and 150 months respectively, and 12 of epithelial, from 53 to 162 months, after the same date.

In the tables, the figures, added together, as before, represent the number of cases. None of those in which death took place as the immediate consequence of the operation have been included.

The cancers of the larynx, œsophagus, rectum, and bladder have been excluded, as they would appear on one side only of the table, viz., among those not operated on.

Duration of life after first observance of cancer.

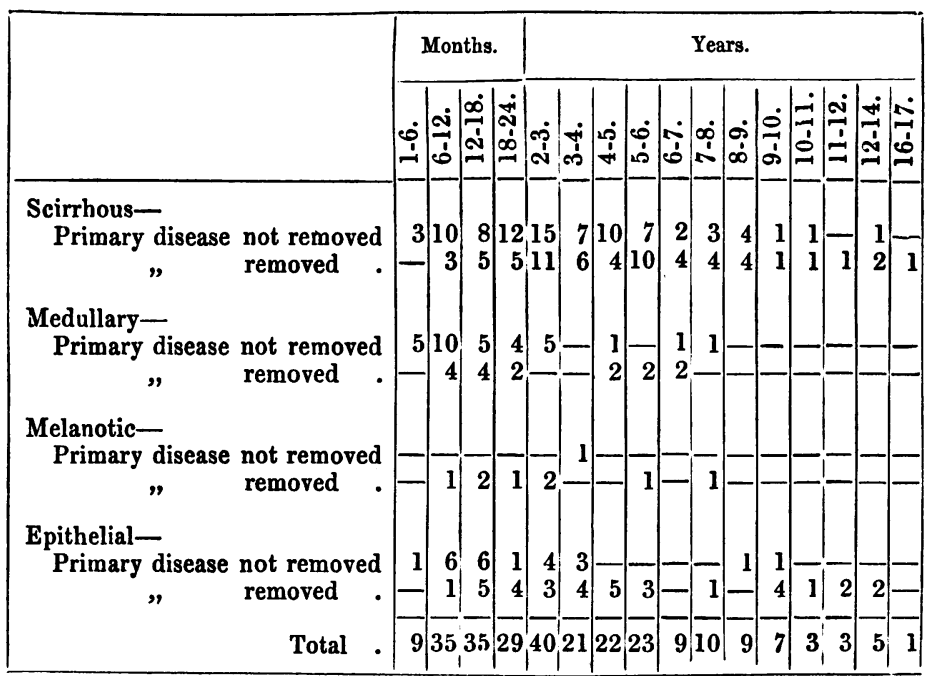


The average length of life taken from this table is-

\begin{tabular}{|c|c|c|c|c|c|c|}
\hline \multicolumn{2}{|c|}{ Scirrhous cancer } & \multicolumn{2}{|c|}{$\begin{array}{c}\text { Primary disease } \\
\text { not removed. } \\
\text {. } 43.0 \text { months }\end{array}$} & & \multicolumn{2}{|c|}{$\begin{array}{l}\text { Primary disease } \\
\text { removed. } \\
55 \cdot 6 \text { months. }\end{array}$} \\
\hline Medullary & ” & . $20 \cdot 0$ & ” & & $33 \cdot 4$ & ” \\
\hline Melanotic & , & - & & & $44 \cdot 6$ & \\
\hline Epithelial & , & $27 \cdot 4$ & ״ & & $57 \cdot 6$ & \\
\hline
\end{tabular}

In cancer of all kinds the average length of life is-

Primary disease not removed . $\quad$. 30.0 months.

" removed . . $47 \cdot 8$ "

It is hardly necessary to observe that the striking difference in the length of life, in all the varieties of cancer, according as the primary tumour is or is not removed, is due, in a great measure, to the more favorable cases being those for which an operation would be most often undertaken. But though it would be impossible to tell exactly how far this may account for the contrast, it seems almost certain that the operation in itself has a tendency to prolong life. This, however, is not a question which statistics alone would answer.

The greatest contrast is shown between the epithelial cancers operated on and those not interfered with; and this corresponds also with the great contrast between the chronic, superficial, and easily removed form on the one side, and the acute, rapidly infiltrating form on the other.

The rate of mortality here given for the two classes (including all kinds of cancer) differs from that stated in $\mathbf{M r}$. Paget's lectures, the difference being probably due to the greater care exercised in the selection of cases for operation during the last ten years.

\section{Influence of age on the duration of life.}

The age of patients seems to have but little influence in determining the length of life, except by its connexion with the kind of cancer.

Amongst those not operated on (including the cases in 
all the organs), the duration of life at each age was as follows :

Age.

0 to 30 years

30,50

50,90
Average length of life.

- $19 \cdot 0$ months.

- $34 \cdot 7$ "

- $32 \cdot 1$,

Amongst those operated on :

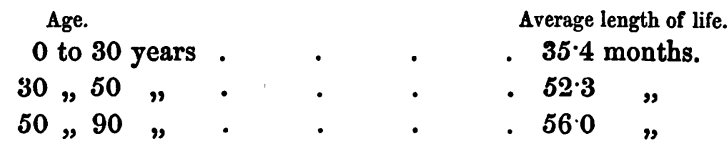

Influence of the seat of cancer on life.

In only a few of the several organs in which the whole duration of the disease was known, were the cases suffciently numerous to allow of an average being taken for them separately; and in three only, the breast, the tongue, and the bones, were the numbers enough to compare those operated on with the rest. The average duration of life in each was as follows :

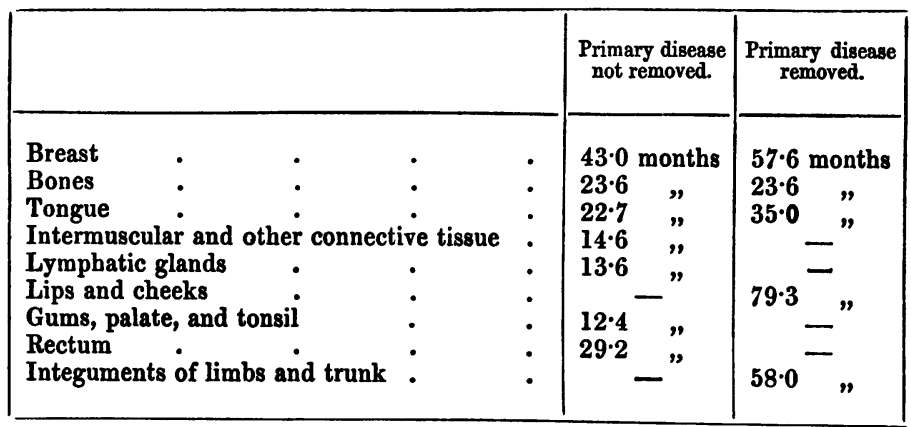

The difference in the fatality of epithelial cancer according to its seat in the tongue or integuments is well marked.

It would seem also from this table that the operation made no difference in the length of life in cases of medullary cancer affecting the bones. 
The average duration of life given in Mr. Sibley's paper for cancer of all kinds not operated on is 23.6 months, a number smaller than that given here. Part of this difference may be accounted for by his not including the patients still living, and by cancers of the uterus forming a considerable proportion of the whole number of his cases, the average for the latter being only $14 \cdot 1$ months.

The average in the same paper for cancer of the breast not removed is $32 \cdot 25$ months, and when removed (not including the deaths from operation) $56 \cdot 6$, the latter number very nearly corresponding with that given here.

The average duration of life of epithelial cancer not removed is, in Mr. Sibley's paper, fifty-three months, but it is deduced from cancer of the lips only.

\section{Influence of early and late operation.}

Concerning the influence which early or late operation may have in prolonging life, almost the same remarks are applicable with those which were made about the recurrences.

The following table has been constructed from 124, cases.

\begin{tabular}{|c|c|c|c|c|}
\hline \multicolumn{3}{|l|}{ Date of operation. } & \multirow{2}{*}{\multicolumn{2}{|c|}{$\begin{array}{c}\text { Average length of life after } \\
\text { operation. } \\
\text { - } \quad 32.9 \text { months. }\end{array}$}} \\
\hline 1 to 6 months & - & - & & \\
\hline $6 " 12 \eta$ & • & . & . $31 \cdot 8$ & , \\
\hline " 2 years & • & • & - $33 \cdot 6$ & ” \\
\hline $2,5 \eta$ & . & . & . 46.7 & " \\
\hline
\end{tabular}

Four cases, in which the operation was performed six to ten years from the beginning of the disease, lived from three to seven years.

As in the cases of recurrence, many of which are included in the present table, so here the inferences which might otherwise be drawn from the date of the operation and its influence on the length of life are rendered void by the acute cancers being those which are the earliest to be removed and to return, and the chronic the latest. All the varieties of cancer come under this rule. 
The whole number of operations recorded in the cases was 239, and the deaths twenty-four: the mortality was almost exactly, therefore, 10 per cent.

The deaths included five amputations of the thigh, two of the leg, twelve removals of the breast, two of the testicle, and one of each of the following:-cervical gland, medullary tumour in the neck, and an epithelial tumour from the cheek. Altogether, there were 109 cases of removal of the breast, and twelve of these died, the mortality being again about 10 per cent.

Duration of life in hospital and private cases compared.

It would be probably necessary to obtain a very much larger number of cases than are taken in the present paper, to settle certainly whether any difference exists, as regards length of life, between hospital and private patients. It seemed, howerer, worth while to compare these two classes so far as was possible here, and the result was as follows. Of cancer of all kinds, in which the duration of life was known and the condition of the patient recorded, there were 87 hospital and 193 private, and the average duration of life was about forty-two months for hospital, and thirty-seven months for private cases.

Excluding cancer of the breast, the average was $36 \cdot 1$ months for the hospital patients and 30.3 for private; and for cancer of the breast alone, about fifty-seven months for hospital, and forty-three for private patients.

The difference between the two classes may, however, be ascribed, at least in part, to a larger proportion of the hospital cases being submitted to operation. 